\title{
Expression of retinol binding protein 4 and nuclear factor- $\kappa B$ in diabetic rats with atherosclerosis and the intervention effect of pioglitazone
}

\author{
WAN ZHOU ${ }^{1}$, SHANDONG YE ${ }^{1}$ and JING LI ${ }^{2}$ \\ Departments of ${ }^{1}$ Endocrinology and ${ }^{2}$ Central Laboratory, Anhui Provincial Hospital, \\ Affiliated to Anhui Medical University, Hefei, Anhui 230001, P.R. China \\ Received February 19, 2015; Accepted March 31, 2016
}

DOI: $10.3892 /$ etm. 2016.3340

\begin{abstract}
This study aims to investigate the expression of retinol binding protein $4(\mathrm{RBP} 4)$ and the activity of nuclear factor-kappa $\mathrm{B}(\mathrm{NF}-\kappa \mathrm{B})$ in diabetic rats with atherosclerosis, and to evaluate the intervention effect of pioglitazone. A total of 75 Wistar rats were randomly divided into four groups: Normal control (NC), diabetic rats (DM1), diabetic rats with atherosclerosis (DM2) and diabetic rats treated with pioglitazone $(\mathrm{DM}+\mathrm{Pio})$. The activity of $\mathrm{NF}-\kappa \mathrm{B}$, the levels of serum and adipose tissue RBP4, fasting plasma glucose (FPG), fasting insulin (FINS), low-density lipoprotein cholesterol (LDL-c), high-density lipoprotein cholesterol (HDL-c), triglycerides (TG) and arteria caudilis systolic blood pressure (SBP) were measured. Percentage of fat mass (PFM), atherogenic index of plasma (AIP) and homeostasis model assessment of insulin resistance (HOMA-IR) were calculated. Compared with the $\mathrm{NC}$ and $\mathrm{DM}+$ Pio groups, all the parameters mentioned above increased significantly in the DM1 and DM2 groups, with the exception that HDL-c decreased. Pearson analysis showed that RBP4 in serum and adipose tissue were positively associated with TG, LDL-c, FINS, PFM, AIP, HOMA-IR, NF-кB, SBP and negatively associated with HDL-c. Multivariable logistic regression analysis showed that serum RBP4 and TG were predictors for the presence of diabetic atherosclerosis. In conclusion, RBP4 may be an effective predictor for diabetic atherosclerosis; pioglitazone is able to decrease RBP4 and $\mathrm{NF}-\kappa \mathrm{B}$, which may partly contribute to its protective effect against diabetic atherosclerosis.
\end{abstract}

Correspondence to: Professor Shandong Ye, Department of Endocrinology, Anhui Provincial Hospital, Affiliated to Anhui Medical University, 17 Lujiang Road, Hefei, Anhui 230001, P.R. China

E-mail: yeshandong123@163.com

Key words: diabetic atherosclerosis, retinol binding protein 4, nuclear factor- $\kappa \mathrm{B}$, pioglitazone

\section{Introduction}

Prior studies (1) have indicated that chronic subclinical inflammation and insulin resistance (IR) are common pathological bases of type 2 diabetes mellitus (T2DM) and atherosclerosis, which are closely associated with inflammation factors and adipokines. Retinol binding protein 4 (RBP4) is a $21 \mathrm{kD}$ protein synthesized in the liver and adipose tissue, whose original function is to deliver vitamin A to its target tissue as a transporter (2). The close association between RBP4, obesity, and T2DM was first described by Yang et al (2) in their study of adipose-specific GLUT4 knockout mice, which demonstrated that serum RBP4 expression levels are elevated in IR mice. Subsequently, elevated RBP4 levels can impair insulin signaling in muscles and increase hepatic glucose output (2). A series of subsequent animal and clinical studies also revealed that RBP4 was highly associated with IR and T2DM and other insulin-resistant states, such as nonalcoholic fatty liver disease and metabolic syndrome (3-6). Nuclear factor-kappa B (NF-кB) is a family of key transcription factors linked to immune response, inflammation, cell survival and apoptosis $(7,8)$. As the most common present heterodimer of NF- $\mathrm{BB}, \mathrm{p} 50 / \mathrm{p} 65$ is able to facilitate transcription of a variety of genes involved in the pathogenesis of diabetic macrovasular diseases (9). Thiazolidinediones, such as pioglitazone, are ligands for the nuclear receptor peroxisome proliferator-activated receptor- $\gamma$ (PPAR- $\gamma$ ), they are widely used as insulin-sensitizing agents that improve glycemic control and have been shown to have potential cardiovascular benefits independent of hypoglycemic effect (10). The aim of the present study was to observe the association among $\mathrm{RBP} 4, \mathrm{NF}-\kappa \mathrm{B}$ and diabetic atherosclerosis and to study the intervention effect of pioglitazone by establishing streptozotocin-induced diabetic and diabetic atherosclerosis rat models.

\section{Materials and methods}

Statement of ethics. The study protocol was approved by the Ethics Committee of Anhui Medical University (Hefei, China), Medical Institution Animal Care and Research Advisory Committee. These animals were maintained according to the guidelines established in 'Guide for the care and use of 
A
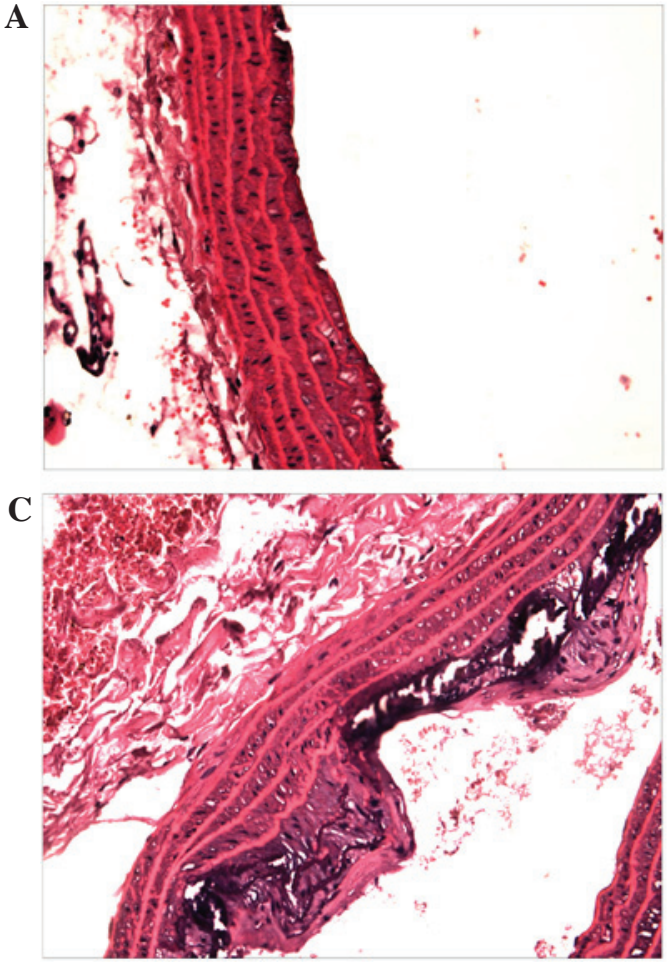

B

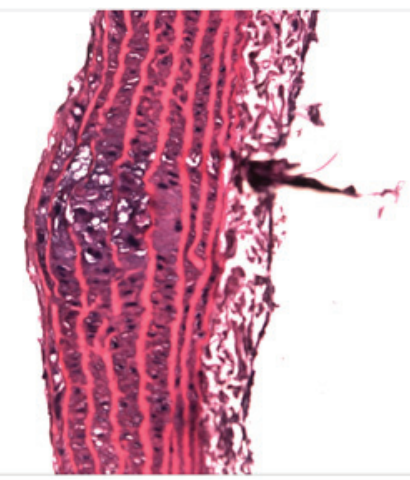

D

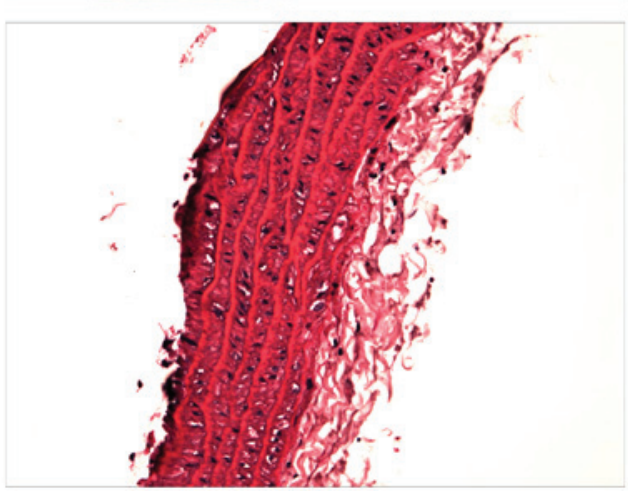

Figure 1. Thoracic aortas (stain, hematoxylin and eosin). (A) Normal control, (B) DM1, (C) DM2 and (D) DM + Pio groups.

laboratory animals' prepared by the Committee on Care and Use of Laboratory Animals of the Institute of Laboratory Animal Resources Commission on Life Sciences, National Research Council, USA (1985) (11).

Animals. A total of 75 male Wistar rats (age, 2 months; weight, 190-210 g) were provided by the experimental animal center of Anhui Medical University, they were housed in clean plastic cages of three or four rats per each and were kept under artificial conditions of light (14/10 h light cycle, light on at 7 a.m.), temperature $\left(23 \pm 2^{\circ} \mathrm{C}\right)$ throughout the experiment. All the rats were randomly assigned to the normal control $(\mathrm{NC}, \mathrm{n}=15)$, diabetic rat (DM1, n=20) and diabetic rats with atherosclerosis (DAM, $\mathrm{n}=40$ ) groups. The rats in the NC group were fed a normal diet, while DM1 group rats were fed a high-fat and high-calorie diet (2.5\% cholesterol, $1 \%$ sodium cholate, $20 \%$ sugar, $10 \%$ lard and $66.5 \%$ basal diet). DAM group rats received vitamin D3 (Shanghai General Pharmaceutical Co., Ltd., Shanghai, China) intragastric administration of a total dose of $600,000 \mathrm{IU} / \mathrm{kg}$ for three days prior to feeding to accelerate artery calcification, then received a high-fat and high-calorie diet (3\% cholesterol, $0.5 \%$ sodium cholate, $0.2 \%$ propylthiouracil, $5 \%$ sugar, $10 \%$ lard and $81.3 \%$ basal diet). All rats had free access to water and food for 4 weeks, and rats in the DM1 and DAM groups were fasted overnight for $12 \mathrm{~h}$ and given the peritoneal injection of a dose of streptozotocin (STZ) $30 \mathrm{mg} / \mathrm{kg}$ (Sigma-Aldrich, St. Louis, MO, USA) in $0.1 \mathrm{~mol} / 1$ citrate buffer $(\mathrm{pH} 4.2)$ while the $\mathrm{NC}$ group were injected with an equivalent volume of citric acid buffer. After $72 \mathrm{~h}$, tail vein blood samples of the rats in these three groups were harvested to assess the plasma glucose, and rats with fasting plasma glucose (FPG) $>7.8 \mathrm{mmol} / \mathrm{l}$ were selected as T2DM models (12). At week 8 after feeding there was a total of 18 and 37 rats with successful modeling in the DM1 and DAM groups, respectively. DAM group rats were then further divided into two groups: Pioglitazone-treated $(\mathrm{DM}+\mathrm{Pio}, \mathrm{n}=22)$ and diabetic atherosclerosis $(\mathrm{DM} 2, \mathrm{n}=15)$. The rats in the $\mathrm{DM}+\mathrm{Pio}$ group were lavaged with pioglitazone $20 \mathrm{mg} / \mathrm{kg} /$ day dissolved in sodium chloride (Huadong Medicine Co., Ltd., Hangzhou, China), while NC, DM1 and DM2 group rats were treated with corresponding sodium chloride per day. FPG and arteria caudilis systolic blood pressure (SBP) were respectively assayed using an Accu-Chek Active System (Roche Diagnostics GmbH, Mannheim, Germany) and a tail artery sphygmomanometer (type, RBP-1; China-Japan Friendship Research Institute, Beijing, China), on a weekly basis.

Collection of specimens. At the 16th weekend, all the rats were sacrificed under anesthesia by peritoneal injection of chloral hydrate $(300 \mathrm{mg} / \mathrm{kg})$ and blood samples were collected from the left ventricles of their hearts. Samples were used to assay for low-density lipoprotein cholesterol (LDL-c), high density lipoprotein cholesterol (HDL-c) and triglycerides (TG), using an automatic biochemical analyzer (HITACHI 7600-020, Hitachi Ltd., Tokyo, Japan). In addition, fasting insulin (FINS) levels were detected using an insulin radioimmunoassay kit (cat. no. S10950120; Atom Hi-Tech Co., Ltd., China). The remaining samples were centrifuged for $20 \mathrm{~min}$ to isolate the supernatant for detection of serum RBP4 using an enzyme-linked immunosorbent assay (ELISA) kit (cat. no. SEA929Hu; USCN Business, Co., Ltd., Wuhan, China). Atherogenic index of plasma (AIP) and homeostasis model assessment of insulin resistance (HOMA-IR) were calculated according to the formulas AIP $=\log$. (TG/HDL-c) and HOMA-IR = FINS x FPG/22.5, respectively. The thoracic aortas were separated and removed for hematoxylin and eosin (HE) staining and the measurement of NF- $\mathrm{KB}$ activity by ELISA (cat. no. 43296; Active Motif, Rixensart, Belgium). 
Adipose tissue in mesenterium, epididymis and peritoneal were extracted for the measurement of percentage of fat mass (PFM). Furthermore, the epididymis adipose tissue were additionally assayed for RBP4 mRNA detection using reverse transcription polymerase chain reaction (RT-PCR) analysis (Takara Biotechnology Co., Ltd., Dalian, China).

ELISA for serum RBP4 expression. Anti-RBP4 polyclonal antibody (concentration, $1 \mu \mathrm{g} / \mathrm{ml}$; cat. no. PAA929Ra01; USCN Business, Co., Ltd.) was pre-coated onto the microwells. The RBP4 protein in the samples was captured by the antibody following incubation at $37^{\circ} \mathrm{C}$ for $1 \mathrm{~h}$. Following extensive washing, a monoclonal antibody specific for RBP4 (dilution, 1:100; cat. no. MAA929Ra21; USCN Business, Co., Ltd.) was added to detect the captured RBP4 protein. For signal development, horseradish peroxidase (HRP)-conjugated antibody (dilution, 1:100; cat. no. SEA929Hu; USCN Business, Co., Ltd.) was added, followed by tetramethyl-benzidine reagent. Sulfuric acid was used to stop color development, and color intensity that was proportional to the quantity of bound protein was measured at $450 \mathrm{~nm}$ (BioTek ELX800 Absorbance Microplate Reader; BioTek Instruments, Inc., Winooski, VT, USA).

ELISA for $N F-\kappa B$ activity. Nuclear protein was extracted using a TransAm nuclear protein extraction kit (Active Motif, Inc.; cat. no. 40010). Buffers including phosphate-buffered saline (PBS), phosphatase inhibitor buffer and hypotonic buffer were prepared prior to nuclear protein extraction, and the tissue samples were then suspended in ice cold-PBS homogenate for centrifugation at $3,000 \mathrm{x}$ g for $5 \mathrm{~min}$. The supernatant was removed and the pellet was resuspended in ice cold-hypotonic buffer, and following centrifugation for $20 \mathrm{~min}$, the nuclear pellet was resuspended in complete lysis buffer and the supernatant was carefully transferred to a tube as nuclear protein extraction. The protein was added to a 96-well plates containing a consensus-binding site of oligonucleotides for $\mathrm{NF}-\kappa \mathrm{B} . \mathrm{NF}-\kappa \mathrm{B}$ activity was evaluated by detecting phosphorylated p65 protein which specifically binds to the immobilized oligonucleotide containing NF- $\kappa \mathrm{B}$ consensus site $\left(5^{\prime}-\mathrm{GGG}\right.$ ACTTTCC-3'). The primary antibody (anti-NF-кB; 1:1,000; cat. no. 43296; Active Motif, Inc., La Hulpe, Belgium) used to detect NF- $\kappa \mathrm{B}$ recognized an epitope on p65 that is accessible only when it is activated and bound to its DNA target. An HRP-conjugated secondary antibody (anti-rabbit; 1:1,000; cat. no. 43296; Active Motif, Inc.) provided a sensitive colorimetric readout that was quantified by spectrophotometry at 450 nm (BioTek ELX800 Absorbance Microplate Reader).

$R T$-PCR detection for adipose tissue RBP4 mRNA. Total RNA was extracted using TRIzol reagent (Invitrogen; Thermo Fisher Scientific, Inc., Carlsbad, CA, USA). RNA $(2 \mu \mathrm{g})$ was reverse transcribed to first-strand cDNA following treatment with DNase to remove contaminating DNA. Template RNA, Oligo(dT)20, dNTP mix, and nuclease-free water were combined in a PCR tube. RNase inhibitor and reverse transcriptase were added to the PCR tube and the tube was placed in T100 thermal cycler (Bio-Rad Laboratories, Inc., Hercules, CA, USA) for one cycle that includes annealing, extending and then inactivating reverse transcriptase. Subsequently, $2.5 \mu 1 \mathrm{cDNA}$ was used as a template for amplification of RBP4, and sterile distilled water was used

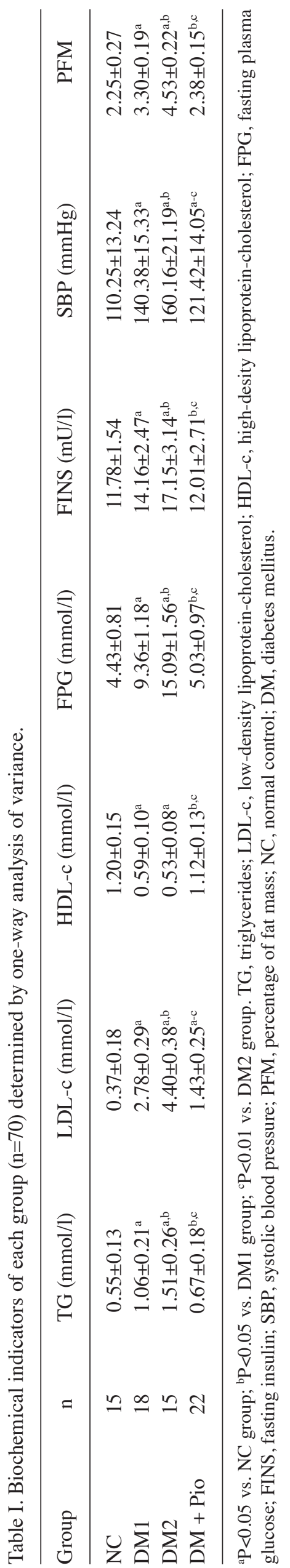




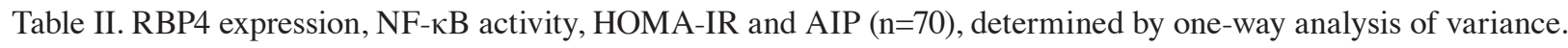

\begin{tabular}{|c|c|c|c|c|c|c|}
\hline Group & $\mathrm{n}$ & RBP4 (ng/ml) & $\begin{array}{l}\mathrm{NF}-\kappa \mathrm{B} \\
\text { activity }\end{array}$ & HOMA-IR & AIP & $\begin{array}{l}\text { Adipose tissue } \\
\text { RBP4 mRNA }\end{array}$ \\
\hline $\mathrm{NC}$ & 15 & $19.47 \pm 2.83$ & $0.35 \pm 0.07$ & $1.93 \pm 0.92$ & $-0.10 \pm 0.27$ & $0.90 \pm 0.14$ \\
\hline DM1 & 18 & $29.86 \pm 1.69^{a}$ & $0.67 \pm 0.11^{\mathrm{a}}$ & $6.04 \pm 1.32^{\mathrm{a}}$ & $0.30 \pm 0.13^{\mathrm{a}}$ & $1.36 \pm 0.18^{a}$ \\
\hline DM2 & 15 & $56.52 \pm 2.14^{\mathrm{a}, \mathrm{b}}$ & $1.43 \pm 0.14^{\mathrm{a}, \mathrm{b}}$ & $11.68 \pm 1.83^{\mathrm{a}, \mathrm{b}}$ & $0.53 \pm 0.22^{\mathrm{a}, \mathrm{b}}$ & $2.12 \pm 0.22^{\mathrm{a}, \mathrm{b}}$ \\
\hline $\mathrm{DM}+\mathrm{Pio}$ & 22 & $31.03 \pm 3.10^{\mathrm{a}, \mathrm{c}}$ & $0.73 \pm 0.09^{\mathrm{a}, \mathrm{c}}$ & $3.15 \pm 1.17^{\mathrm{a}-\mathrm{c}}$ & $0.04 \pm 0.23^{b, c}$ & $0.85 \pm 0.12^{\mathrm{b}, \mathrm{c}}$ \\
\hline
\end{tabular}

${ }^{\mathrm{a}} \mathrm{P}<0.05$ vs. NC group; ${ }^{\mathrm{b}} \mathrm{P}<0.05$ vs. DM1 group; ${ }^{\mathrm{P}}<0.01$ vs. DM2 group. RBP4, retinol binding protein 4 ; NF- $\mathrm{kB}$, nuclear factor-kappa $\mathrm{B}$; HOMA-IR, homeostasis model assessment of insulin resistance; AIP, atherogenic index of plasma; NC, normal control; DM, diabetes mellitus.

instead of cDNA as a negative control. Each sample simultaneously amplified $\beta$-actin as intra-reference. The primers were 5'-TGCAGGGTGAGCAGCTTCAG-3' (upstream primer), 5'-CACTTCCCAGTTACTCAGAAG-3' (downstream primer) for RBP4, generating a 198 bp fragment. 5'-GAGGGAAAT CGTGCGTGAC-3' (upstream primer), 5'-TAGGAGCCAGGG CAGT-AATCT-3' (downstream primer) for $\beta$-actin, generating a 353 bp fragment. The PCR conditions included denaturation at $94^{\circ} \mathrm{C}$ for $30 \mathrm{sec}$, and annealing at $55^{\circ} \mathrm{C}$ for $15 \mathrm{sec}$ and extension at $72^{\circ} \mathrm{C}$ for $30 \mathrm{sec}$ followed by 35 cycles. The amplified products were subjected to $1.5 \%$ agarose gel electrophoresis (BioSens 805; Bio-Tech Co., Ltd., China) and images of the bands were captured followed by analysis of the optical density (Gel-Pro Analyzer image analysis software version 3.0; Media Cybernetics, Inc., Rockville, MD, USA). The expression of RBP4 mRNA was normalized against that of $\beta$-actin.

Statistical analysis. Data were analyzed using SPSS software, version 13.0 (SPSS, Inc., Chicago, IL, USA). Normally distributed data were presented as the mean \pm standard deviation. The measurement data of multiple groups were compared with one-way analysis of variance, the comparison between two groups was performed with LSD $t$-Test; Pearson correlations were adopted to note the correlation. Multivariable logistic regression analysis was used to calculate the odds ratio and $95 \%$ confidence intervals for diabetic atherosclerosis. $\mathrm{P}<0.05$ was considered to indicate a statistically significant difference.

\section{Results}

Thoracic aortas HE staining. The structure of thoracic aortas in the NC group had no significant pathological changes (Fig. 1A). In the DM1 group, the aortic tunica intima was rough, the arrangement of the smooth muscle cells was regular (Fig. 1B). In the DM2 group, the aortic tunica intima was thickened and protruded into the lumen; the arrangement of the smooth muscle cells was irregular; foam cells and calcification was observed diffusively (Fig. 1C). In the DM + Pio group, the three-layer structure of the vessel wall was distinct; the aortic tunica intima was smooth and thin; the arrangement of the smooth muscle cells was regular (Fig. 1D).

Biochemical indicators. At week 16 after feeding, weights of the rats in the NC, DM1, DM2 and DM + Pio groups were $451 \pm 19,520 \pm 22,557 \pm 25$ and $490 \pm 17 \mathrm{~g}$ respectively. The

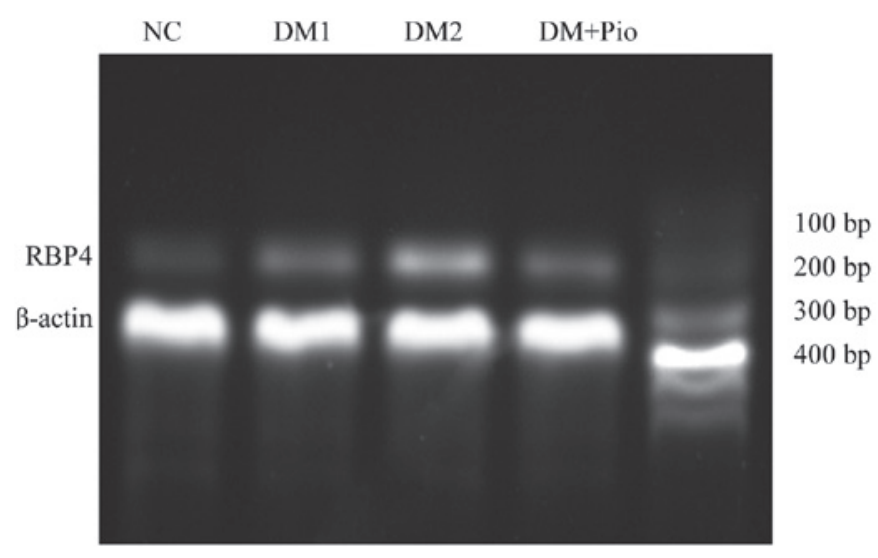

Figure 2. Comparison of adipose tissue RBP4 mRNA. NC, normal control; $\mathrm{DM}$, diabetes mellitus; RBP4, retinol binding protein 4.

biochemical results were presented in Table I: Elevated levels of TG, LDL-c, FPG, FINS, SBP, PFM and reduced HDL-c were detected in the DM1 and DM2 groups compared with the NC group. Following eight weeks of treatment with pioglitazone, HDL-c levels increased and TG, LDL-c, FPG, FINS, SBP, PFM decreased significantly in the DM + Pio groups compared with the DM1 and DM2 groups.

Expression of RBP4, the activity of $N F-\kappa B, H O M A-I R$ and AIP. As shown in Table II, compared with the NC group, these indicators increased in the DM1 and DM2 groups, and the increase in the DM2 group was more significant. Following eight weeks of therapy with pioglitazone, the indicators decreased in the $\mathrm{DM}+$ Pio group compared with the and DM2 group. The levels of RBP4 and the NF- $\mathrm{BB}$ activity increased in the DM + Pio group compared with the DM1 group, but all other variables decreased in the DM + Pio group compared with the DM1 group. Fig. 2 showed that the expression of epididymal adipose tissue RBP4 mRNA in the NC group $(0.9 \pm 0.14)$ was significantly reduced compared with the DM1 $(1.36 \pm 0.18)$ and DM2 $(2.12 \pm 0.22)$ groups, and pioglitazone administration appeared to downregulate this expression $(0.85 \pm 0.12)$.

Statistical results. Pearson analysis showed that RBP4 in the rat serum and epididymal adipose tissue was positively associated with TG, LDL-c, FINS, PFM, AIP, HOMA-IR, NF-кB and SBP, while being negatively associated with HDL-c. There was no significant correlation between adipose tissue RBP4 
Table III. Analysis of the correlation between RBP4 and the indicators of DM groups ( $\mathrm{n}=55)$, determined by Pearson's correlation analysis.

\begin{tabular}{lcccccccccr}
\hline Variable & TG & HDL-c & LDL-c & FPG & FINS & PFM & AIP & HOMA-IR & NF-kB & SBP \\
\hline Serum RBP4 & & & & & & & & & & \\
r & 0.329 & -0.363 & 0.399 & 0.406 & 0.562 & 0.550 & 0.432 & 0.663 & 0.481 & 0.449 \\
P & 0.014 & 0.006 & 0.003 & 0.002 & $<0.001$ & $<0.001$ & 0.001 & $<0.001$ & $<0.001$ & 0.001 \\
Adipose tissue RBP4 & & & & & & & & & & \\
r & 0.498 & -0.421 & 0.362 & 0.116 & 0.326 & 0.470 & 0.429 & 0.371 & 0.371 & 0.561 \\
P & $<0.001$ & 0.001 & 0.007 & 0.397 & 0.015 & $<0.001$ & 0.001 & 0.005 & 0.005 & $<0.001$ \\
\hline
\end{tabular}

RBP4, retinol binding protein 4; DM, diabetes mellitus; TG, triglycerides; HDL-c, high-density lipoprotein-cholesterol; LDL-c, low-desity lipoprotein-cholesterol; FPG, fasting plasma glucose; FINS, fasting insulin; PFM, percentage of fat mass; AIP, atherogenic index of plasma; HOMA-IR, homeostasis model assessment of insulin resistance; NF- $\mathrm{B}$, nuclear factor-kappa B; SBP, systolic blood pressure.

Table IV. Multivariable logistic regression analysis $(\mathrm{n}=55)$, as determined by multivariate logistic regression.

\begin{tabular}{lccccccc}
\hline Variable & & & & & \multicolumn{2}{c}{$95 \%$ CI } \\
\cline { 5 - 8 } Serum RBP4 & B & SE & Wald & Sig & OR & Lower & Upper \\
TG & 0.343 & 0.137 & 6.236 & 0.013 & 1.409 & 1.188 & 2.035 \\
Constant & 0.165 & 0.072 & 5.256 & 0.031 & 1.179 & 1.093 & 1.475 \\
\hline
\end{tabular}

CI, confidence interval; RBP4, retinol binding protein 4; TG, triglycerides; B, $\beta$-value; SE, standard error; Wald, $\chi^{2}$; Sig, significance; OR, odds ratio.

mRNA expression and serum RBP4 levels (Table III). The presence of atherosclerosis was used as dependent variable and the factors in Tables I and II were used as independent variables in T2DM groups (DM1, DM2 and DM + Pio). Multivariable logistic regression analysis showed that serum RBP4 (OR=1.409, 95\% CI=1.188-2.305) and TG $(\mathrm{OR}=1.179$, 95\% CI=1.093-1.475) were significant predictors of diabetic atherosclerosis (Table IV), the equation (obtained by logistic regression analysis) was as follows:

$$
\mathrm{y}=\operatorname{LogitP}=1.074+0.343^{*} \mathrm{RBP} 4+0.165^{*} \mathrm{TG}
$$

\section{Discussion}

$\mathrm{NF}-\kappa \mathrm{B}$ is a family of key transcription factors associated with regulatory pathways generally underlying inflammatory processes (13), and T2DM is associated with low-grade chronic inflammation, in part due to the activation of $\mathrm{NF}-\kappa \mathrm{B}$ (14). In the present study, $\mathrm{NF}-\kappa \mathrm{B}$ activity increased in the DM1 group and was highest in the DM2 group, which indicated that $N F-\kappa B$ played a critical role in the initiation and progression of diabetic atherosclerosis. NF- $\mathrm{BB}$ binds to the inhibitory protein $\mathrm{I} \kappa \mathrm{B}$ in the cytoplasm, and its transcriptional activity can be induced by a variety of atherogenic stimuli including inflammatory cytokines, T2DM and oxidized LDL (15). When T2DM occurs, the mitogen-activated protein kinase conductive gateway and protein kinase $\mathrm{C}$ pathway are activated by increased glycation end products and reactive oxygen species, which leads to the dissociation of $\mathrm{I} \kappa \mathrm{B}$ from $\mathrm{NF}-\kappa \mathrm{B}$ (16). Following dissociation, $\mathrm{NF}-\kappa \mathrm{B}$ is able to enter the nucleus and bind to specific $\kappa \mathrm{B}$ sequence which exists in the promoter or enhancer of specific gene, and induce the synthesis of adhesion molecules and chemokines, ultimately leading to the activation of endothelium and the occurrence of atherosclerosis (17).

According to the present results, RBP4 levels increased in the DM1 and DM2 groups, and more significantly in the DM2 group. These findings are consistent with previous results reported by Vergés et al (18). Cabré et al (19) observed that RBP4 would increase in patients with T2DM complicated with coronary heart diseases, and that if levels of RBP4 increased by $1 / 4$, the risk of cardiovascular diseases would increase by 2.5 times. A recent study (20) demonstrated that the levels of RBP4 had already increased in the early stages of the development of T2DM complicated with atherosclerosis. In the present study, RBP4 was positively correlated with TG, LDL-c, FINS, HOMA-IR, PFM, AIP, NF- $\mathrm{BB}$ and SBP, and negatively correlated with HDL-c following correlation analysis. In addition, high levels of TG and LDL-c and low levels of HDL-c were parameters of dyslipidemia, high levels of $\mathrm{NF}-\kappa \mathrm{B}$ a parameter of inflammation, and high systolic blood pressure a parameter of hypertension. Although the exact mechanisms are not entirely clear, RBP4 may exert this effect via the following mechanisms: i) IR: several studies have indicated that RBP4 is correlated with IR in T2DM $(2,21)$, and is able to negatively regulate phosphatidylinositol 3 kinase activity and insulin receptor substrate 1 tyrosine phosphorylation, induce phosphoenolpyruvate carboxy 
kinase expression in the liver and weaken the insulin signaling pathway, which leads to IR and T2DM. ii) Lipid metabolism disorder: A prior study (22) indicated that RBP4 may be associated with oxidized LDL and involved in the progression of atherosclerosis. As a retinol binding transporter protein, RBP4 has a moderating effect for retinol concentration which is the precursor of retinoic acid $\mathrm{X}$ receptor, which regulates the expression of glucose and lipid metabolism genes (23). Thus, RBP4 may participate in the occurrence of diabetic atherosclerosis through disturbance of lipid metabolism in muscle and/or liver. iii) Inflammation: Yao-Borengasser et al (24) found that visceral adipose tissue RBP4 was positively associated with lipid inflammatory factors (monocyte chemoattractant protein-1 and CD68). In the present study, RBP4 was observed to be positively associated with $\mathrm{NF}-\kappa \mathrm{B}$, in which numerous gene enhancers have binding sites. Munkhtulga et al (25) found that nuclear transcription factor activator protein sequence was discovered in the RBP4 5' flanking region. Hence, RBP4 may be affected by $\mathrm{NF}-\kappa \mathrm{B}$ regulation and participate in the inflammatory mechanism underlying atherosclerosis; however, the specific mechanism requires further investigation.

The PPAR- $\gamma$ agonist pioglitazone is an anti-diabetic and anti-atherosclerotic agent, which regulates the transcription of genes encoding proteins involved in insulin sensitivity and lipid metabolism (26). Potential roles for pioglitazone as therapeutic strategy in diabetic atherosclerosis have been indicated in multiple studies $(27,28)$. Yang et al (2) reported that pioglitazone is able to reduce RBP4 levels in adipose-specific glucose transporter type 4 (GLUT4) knockout mice, and it appeared to decrease RBP4 levels by increasing GLUT4 expression. Furthermore, pioglitazone is able to inhibit the activity of activator protein 1 and NF- $\kappa B$, reduce TNF- $\alpha$ (29) and alleviate the inflammatory response, thereby preventing the progression of atherosclerosis. In the present study, pioglitazone appeared to lower RBP4 levels and NF- $\mathrm{BB}$ activity and alleviate morphological changes associated with atherosclerosis, which suggested that pioglitazone could prevent diabetic atherosclerosis partially by decreasing RBP4 and NF- $\kappa \mathrm{B}$ activity.

In summary, RBP4 and $\mathrm{NF}-\kappa \mathrm{B}$ appear to be risk factors for diabetic atherosclerosis, and RBP4 may be involved in the occurrence of atherosclerosis by IR, inflammation and lipid metabolism disorders. Furthermore, pioglitazone is able to reduce RBP4 levels and $N F-\kappa B$ activity. Thus, pioglitazone had protective effects against diabetic atherosclerosis in addition to the hypoglycemic effect, which was partially associated with the relief of excessive inflammation, the improvement of lipid metabolism and the elevation of insulin sensitivity. The precise mechanisms underlying these effects remain unclear and require further investigation.

\section{Acknowledgements}

This study was supported by grants from the Project of Provincial Natural Science Research of University of Anhui Province of China (No. KJ2012Z178).

\section{References}

1. Lyon CJ, Law RE and Willa A: Minireview: Adiposity, inflammation and atherogenesis. Endocrinology 144: 2195-2200, 2003.
2. Yang Q, Graham TE, Mody N, Preitner F, Peroni OD, Zabolotny JM, Kotani K, Quadro L and Kahn BB: Serum retinol binding protein contributes to insulin resistance in obesity and type 2 diabetes. Nature 436: 356-362, 2005.

3. Lin CJ, Chu NF, Hung YJ, Chang JB, He CT, Hsiao FC and Hsieh $\mathrm{CH}$ : The association of retinol binding protein 4 with metabolic syndrome and obesity in adolescents: The effects of gender and sex hormones. Clin Pediatr (Phila) 52: 16-23, 2013.

4. Li F, Xia K, Sheikh MS, Cheng J, Li C and Yang T: Retinol binding protein 4 promotes hyperinsulinism-induced proliferation of rat aortic smooth muscle cells. Mol Med Rep 9: 1634-1640, 2014.

5. Wolf G: Serum retinol-binding protein: A link between obesity, insulin resistance, and type 2 diabetes. Nutr Rev 65: 251-256, 2007.

6. Terra X, Auguet T, Broch M, Sabench F,Hernández M, Pastor RM, Quesada IM, Luna A, Aguilar C, del Castillo D and Richart C: Retinol binding protein-4 circulating levels were higher in nonalcoholic fatty liver disease vs. histologically normal liver from morbidly obese women. Obesity (Silver Spring) 21: 170-177, 2013.

7. Haddad JJ and Abdel-Karim NE: NF-кB cellular and molecular regulatory mechanisms and pathways: Therapeutic pattern or pseudoregulation? Cell Immunol 271: 5-14, 2011.

8. Chen P, Migita S, Kanehira K, Sonezaki S and Taniguchi A: Development of sensor cells using NF- $\kappa$ B pathway activation for detection of nanoparticle-induced inflammation. Sensors (Basel) 11: 7219-7230, 2011.

9. Xiang M, Wang J, Zhang Y, Ling J and Xu X: Attenuation of aortic injury by ursolic acid through RAGE-Nox-NF- $\kappa B$ pathway in streptozocin-induced diabetic rats. Arch Pharm Res 35: 877-886, 2012

10. Chagger PS, Shaw SM and Williams SG: Review article: Thiazolidinediones and heart failure. Diab Vasc Dis Res 6: 146-152, 2009.

11. National Research Council: Guide for the care and use of laboratory animals: 8th Edition. Bethesda, MD: United States Department of Health and Human Services, National Institutes of Health, NIH publication, 1985.

12. Matteucci E and Giampietro O: Proposal open for discussion: Defining agreed diagnostic procedures in experimental diabetes research. J Ethnopharmacol 115: 163-172, 2008.

13. Monaco C, Andreakos E, Kiriakidis S, Mauri C, Bicknell C, Foxwell B, Cheshire N, Paleolog E and Feldmann M: Canonical pathway of nuclear factor kappa B activation selectively regulates proinflammatory and prothrombotic responses in human atherosclerosis. Proc Natl Acad Sci USA 101: 5634-5639, 2004.

14. Viatour P, Merville MP, Bours V and Chariot A: Phosphorylation of NF- $\kappa \mathrm{B}$ and I $\kappa \mathrm{B}$ proteins, implications in cancer and inflammation. Trends Biochem Sci 30: 43-52, 2005.

15. Sun X, He S, Wara AK, Icli B, Shvartz E, Tesmenitsky Y, Belkin N, Li D, Blackwell TS, Sukhova GK, et al: Systemic delivery of microRNA-181b inhibits nuclear factor- $\kappa \mathrm{B}$ activation, vascular inflammation and atherosclerosis in apolipoprotein e-deficient mice. Circ Res 114: 32-40, 2014.

16. Yamamoto $\mathrm{Y}$ and Gaynor RB: IkappaB kinases: Key regulators of the NF-kappaB pathway. Trends Biochem Sci 29: 72-79, 2004.

17. De Winther MP, Kanters E, Kraal G and Hofker MH: Nuclear factor kappa B signaling in atherogenesis. Arterioscler Thromb Vasc Biol 25: 904-914, 2005.

18. Vergés B, Guiu B, Cercueil JP, Duvillard L, Robin I, Buffier P, Bouillet B, Aho S, Brindisi MC and Petit JM: Retinol-binding protein 4 is an independent factor associated with triglycerides and a determinant of very low-density lipoprotein-apolipoprotein B100 catabolism in type 2 diabetes mellitus. Arterioscler Thromb Vasc Biol 32: 3050-3057, 2012.

19. Cabré A, Lázaro I, Girona J, Manzanares J, Marimón F, Plana N, Heras M and Masana L: Retinol-binding protein 4 as a plasma biomarker of renal dysfunction and cardiovascular disease in type 2 diabetes. J Intern Med 262: 496-503, 2007.

20. Xiao Y, Xu A, Hui X, Zhou P, Li X, Zhong H, Tang W, Huang G and Zhou Z: Circulating lipocalin-2 and retinol-binding protein 4 are associated with intima-media thickness and subclinical atherosclerosis in patients with type 2 diabetes. Plos One 8: e66607, 2013

21. Cho YM, Youn BS, Lee H, Lee N, Min SS, Kwak SH, Lee HK and Park KS: Plasma retinol-binding protein-4 concentrations are elevated in human subjects with impaired glucose tolerance and type 2 diabetes. Diabetes Care 29: 2457-2461, 2006 . 
22. Wu J, Shi YH, Niu DM, Li HQ, Zhang CN and Wang JJ: Association among retionl binding protein 4, small dense LDL cholesterol and oxidized LDL levels in dyslipidemia subjects. Clin Biochem 45: 619-622, 2012.

23. Fruebis J, Tsao TS, Javorsehi S, Ebbets-Reed D, Erickson MR, Yen FT, Bihain BE and Lodish HF: Proteolytic cleavage product of 30-kDa adipocyte complement-related protein increases fatty acid oxidation in muscle and causes weight loss in mice. Proc Nati Acad Sci USA 98: 2005-2010, 2001.

24. Yao-Borengasser A, Varma V, Bodles AM, Rasouli N Phanavanh B, Lee MJ, Starks T, Kern LM, Spencer HJ III, Rashidi AA, et al: Retinol binding protein 4 expression in humans: Relationship to insulin resistance, inflammation and response to pioglitazone. J Clin Endocrinol Metab 92: 2590-2597, 2007.

25. Munkhtulga L, Nakayama K, Utsumi N, Yanagisawa Y, Gotoh T, Omi T, Kumada M, Erdenebulgan B, Zolzaya K, Lkhagvasuren T and Iwamoto S: Identification of a regulatory SNP in the retinol binding protein 4 gene associated with type 2 diabetes in Mongolia. Hum Genet 120: 879-888, 2007.
26. Yki-Järvinen H: Thiazolidinediones. N Engl J Med 351: 1106-1118, 2004.

27. Takagi T, Yamamuro A, Tamita K, Yamabe K, Katayama M, Mizoguchi S, Ibuki M, Tani T, Tanabe K, Nagai K, et al: Pioglitazone reduces neointimal tissue proliferation after coronary stent implantation in patients with type 2 diabetes mellitus: An intravascular ultrasound scanning study. Am Heart J 146: E5, 2003.

28. Dormandy JA, Charbonnel B, Eckland DJ, Erdmann E, Massi-Benedetti M, Moules IK, Skene AM, Tan MH, Lefèbvre PJ, Murray GD, et al: Secondary prevention of macrovascular events in patients with type 2 diabetes in the PRO active study (PROspective pioglitazone clinical trial in macroVascular events): A randomised controlled trial. Lancet 366: 1279-1289, 2005.

29. Ozasa H, Ayaori M, Iizuka M, Terao Y, Uto-Kondo $H$ Yakushiji E, Takiguchi S, Nakaya K, Hisada T, Uehara Y, et al: Pioglitazone enhances cholesterol efflux from macrophages by increasing ABCA1/ABCG1 expressions via PPAR- $\gamma / \mathrm{LXR} \alpha$ pathway: Findings from in vitro and ex vivo studies. Atherosclerosis 219: 141-150, 2011. 